\title{
Numerical studies influence configuration fairing flap track airfoil type naca 4412 and naca 6412 character unmanned aerial vehicle (UAV)
}

\author{
Handrico Ramelan Pratama ${ }^{1}$, and Muhammad Agung Bramantya ${ }^{1, *}$ \\ ${ }^{1}$ Universitas Gadjah Mada, Department of Mechanical \& Industrial Engineering, Yogyakarta, Indonesia
}

\begin{abstract}
Wings have a function of changing the air flowing into force lift, and drag. It can reduce the drag is fairing flap track, where its function can reduce the obstacles caused by the effects of compressibility, fairing flap track also has a major influence on reducing the coefficient drag on airfoil. In this study, we observed the addition of fairing flap track to airfoil, fairing inspired by Sailfish and Blue Shark fish, its fins known to have speeds of $60 \mathrm{~km} / \mathrm{h}$. The independent variable in this research is compare airfoil NACA 4412 and NACA 6412, while the dependent variable is influence of fairing flap track configuration on unmanned aerial vehicle (UAV) character by knowing coefficient lift, coefficient drag and lift to drag ratio using software computational fluid dynamic (CFD). Simulation results know that the coefficient drag airfoil NACA 4412 decreased $0.3 \%$, coefficient lift decreased $0.5 \%$ and coefficient drag airfoil NACA 6412 also decreased $0.4 \%$, coefficient lift decreased $0.7 \%$. It can be concluded that the addition of fairing on airfoil is very influential in reducing the value of coefficient drag and improve the coefficient lift on airfoil.
\end{abstract}

\section{Introduction}

The aerodynamic efficiency of UAV is a model needed studied. because of the design of the UAV are good, efficiency in influence by the fluid flow on aerodynamic heavily influenced by surrounding distribution model [1]. One of the most important is can reduced the fuel so that the plane can fly with a long time. UAV wing aerodynamic influence on the performance of unmanned aerial vehicles (UAVs), on the other hand because of the thin air, flying conditions with low operating pressure, low Reynolds numbers (millions of magnitude), so as to meet the requirements of the unmanned aerial vehicle (uav) great burden, the need to increase lift. so that way lift can affect the stability [2]. Knowledge of basic aerodynamics with a good flow characteristics can lift the aircraft surface is one way to improve the performance of the aircraft in an aerodynamic and maneuvering cruise conditions, and easily controlled [3]. The pressure gradient caused by the pressure difference between the top or bottom of the fuselage resulting in a vortex generator at the trailing edge. the influence of encouragement so pull that resulted in the difference in speed is called the induced drag [4].

The low Reynolds number, Because the difference in the speed of the flow so that the flow can separate the vortex flow at the side of the airfoil section form to participate. layers limit on the upper surface of the airfoil in the incident remains laminar pressure at the beginning of the recovery, so that laminar flow is less resistant in an adverse pressure gradient, flow separation may occur at the leading edge of the airfoil. [5]. Vortex generator $(V G)$ is a method which is used as a tool for separation of the flow controller on some aircraft in the last few years [3]. So this technique can control the flow of a fluid flow after on airfoil. Vortex Generators have an important role in reducing the flow of fluid flow on airfoil thus increasing the ratio of Lift to Drag [6].

\subsection{Vortex generator}

A stream flows at high speed will result in a difference of pressure and speed of the so called "vortex lift", this lift force increases with increasing angles of attack. vortex Breakdown phenomena can be determined on the results of numerical simulation and experiments [7]. Separation flow and vary the flow layer significantly will reduce the drag pressure, improve aircraft performance and improve lift [5].

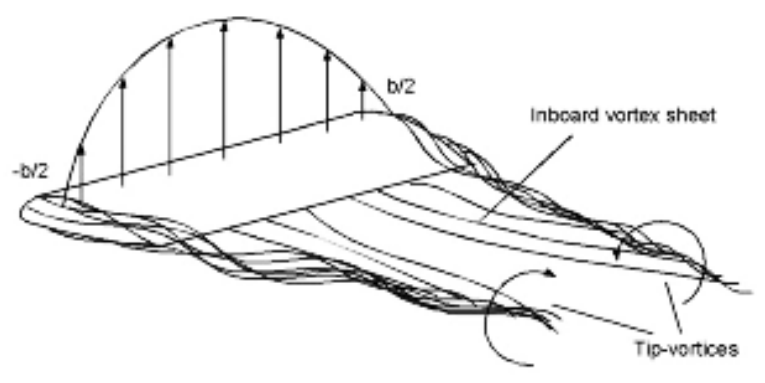

Fig. 1. Tip vortex flow [8].

* Corresponding author: bramantya@ugm.ac.id 
The aerodynamic science vortex was also influenced by the speed of the flow caused by the difference in pressure, the flow vortex can also reduced fuel consumption and slow the stall on the airfoil. With the well known consequences (vibration, drag increase and loss of control). In this search of the best formulation in separation, it is necessary to bring momentum to the layer boundary (BL) to allow it to increase the gradient of pressure against form [9]. Generally, vortex generators are designed as either passive or active devices. The effectiveness of vortex generator against the measure have a fixed position and orientation on the surface [5]. If the flow has decreased so that adjacent whirlpool can be more efficient in reducing flow separation [10]. The dynamics of the flow which flows can be in the approach by using Computational fluid dynamics (CFD). Designing with CFD can easily either using a well designed and better results [3]. This research is knowing the different types of NACA 4412 and NACA 6412 comparison with the addition two model of fairing as a basic of references for airfoil characteristics and to know after using fairing. The most important thing is addition to get the value of the coefficient drag, coefficient lift and also knowing the kind of stream flow around the airfoil. This research also provides the basic for the consideration of the development of UAV in Universitas Gadjah Mada.

\section{Methodology}

The study tried to find out the flap track fairing addition phenomenona against the airfoil configurations. Airfoil a significant role for a unmanned aerial vehicle (UAV), the plane can fly in the utilizing the caused of the forces acting on the airfoil.

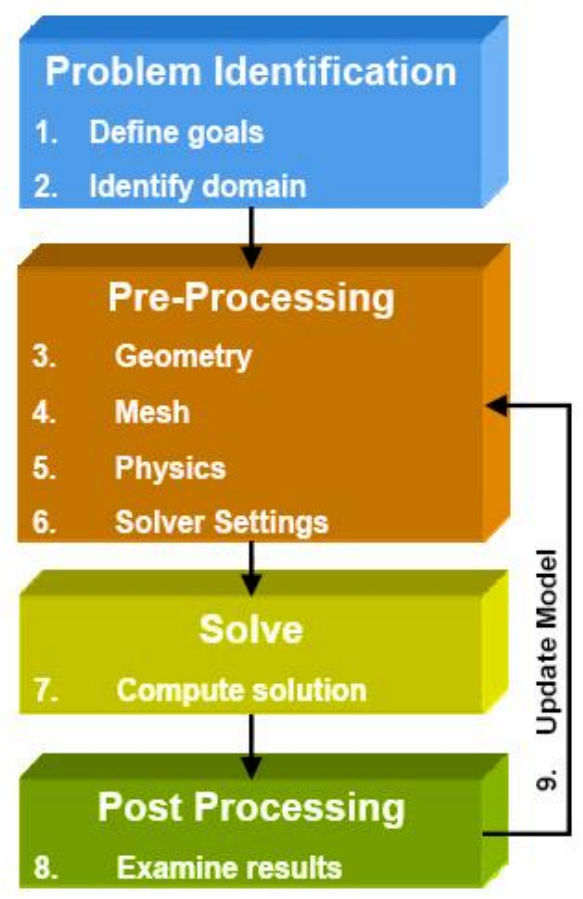

Fig. 2. Flowchart research.
This study has several stages, which are basic in determining a problem then get the results of the process can highly considered in for precision/accuracy of data the results of the process.

\subsection{Problem identification}

The unmanned aerial vehicle (UAV) is design for monitoring purposes, durability and time cruising is very calculated. Airfoil is one very important thing in a unmanned aerial vehicle (UAV), where airfoil can also reduced fuel use, because they would affect the airfoil's variation coefficient lift, coefficient drag.

\subsection{Pre-processing}

This research uses a model Naca 4412 and Naca 6412 variations with the addition of fairing on the airfoil.

This research uses a structure mesh, it has advantages in capture a flow phenomena that occurred and the result of the simulation is more accurate.

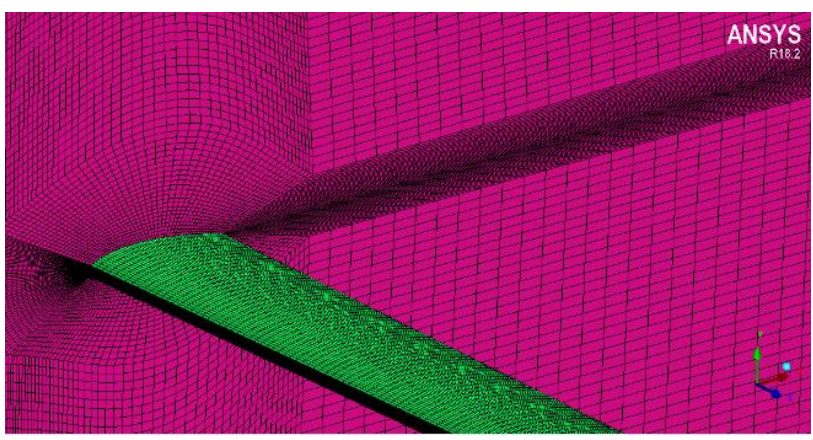

Fig. 3. Distribustion mesh around airfoil.

In this research is to know the influence of the addition of the fairing against the flow pattern and the most significant thing is to know the value of coefficient lift, coefficient drag. The based for consideration in use on unmanned aerial vehicle (UAV).

Table 1. Meshing characteristic.

\begin{tabular}{|c|c|c|}
\hline \multicolumn{3}{|c|}{ Variable } \\
\hline Meshing Type & Hexahedral & Hexahedral \\
\hline Model & Element Number & $\begin{array}{c}\text { Average } \\
\text { Skewness }\end{array}$ \\
& 4666311 & 0.55003 \\
\hline Model 1 & 4781034 & 0.43123 \\
\hline Model 2 & 4912041 & 0.62012 \\
\hline Model 3 & 4512410 & 0.41029 \\
\hline Model 4 & 4612103 & 0.53183 \\
\hline Model 5 & 4780122 & 0.48381 \\
\hline Model 6 & & \\
\hline
\end{tabular}

\section{3 solve}

Determine process simulation also can an important role, due to the results in the observed should also function of getting result. As for some of the required as follows. 
Table 2. Properties

\begin{tabular}{|c|c|c|}
\hline \multicolumn{3}{|c|}{ Model } \\
\hline \multirow[t]{4}{*}{ Solver } & Solver & Pressure-based \\
\hline & Time & Steady \\
\hline & Velocity & Absolute \\
\hline & Formulation & \\
\hline Energy & Energy & Off \\
\hline \multirow[t]{3}{*}{ Viscous } & Model & K-Omega SST \\
\hline & $\begin{array}{l}\text { Near-wall } \\
\text { treatment }\end{array}$ & $\begin{array}{l}\text { Standard Wall } \\
\text { Functions }\end{array}$ \\
\hline & Model Constan & Defaults \\
\hline Momentum & Velocity & $\begin{array}{l}\text { Magnitude, } \\
\text { Normal to } \\
\text { Boundary }\end{array}$ \\
\hline \multirow[t]{3}{*}{ Inlet } & $\begin{array}{c}\text { Velocity } \\
\text { Magnitude }\end{array}$ & $\begin{array}{c}27 \mathrm{~m} / \mathrm{s}=100 \\
\mathrm{~km} / \mathrm{h}\end{array}$ \\
\hline & Supersonic/Initial & $0 \mathrm{~Pa}$ \\
\hline & Gauge Pressure & \\
\hline
\end{tabular}

The monitoring mission in the region, the unmanned aerial vehicle (UAV) requires speed that can have an impact on the results of the camera, so that the speed of $100 \mathrm{~km} / \mathrm{h}$ or $27 \mathrm{~m} / \mathrm{s}$ is very recommended, because that speed was the unmanned aerial vehicle (UAV) has a consider of fuel endurance and the results of photos region of good quality.

\subsection{Post-processing}

The results of the above research is to get the value of the coefficient lift, coefficient drag and flow phenomena on airfoil section.

\section{Results and discussion}

The observations seen that the results of the fairing on the airfoil turns out the reduced the value of the coefficient drag since, with increasing extents on airfoil geometry basis will increase, but at a broad crosssection of the flow delay vortex at the tip chord. it can be concluded that with a fairing trailing edge separation flow more centered on the fairing and slowing the onset of vortex on the tip chord.

The addition of the fairing on the airfoil can reduced the value of the coefficient lift, coefficient drag caused decline because of changing the lift force occurs at the bottom of the airfoil separation flow solving. Where the focus of flow occurs in the caused by the fairing, so the fairing has functions like the winglet. Other functions of the fairing can also slow the vortex generation occurs and can avoid the downwash caused by vortex flow.

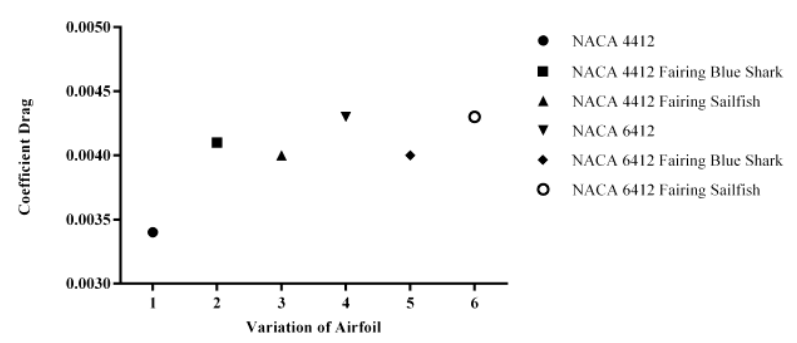

Fig. 4. Coefficient drag.

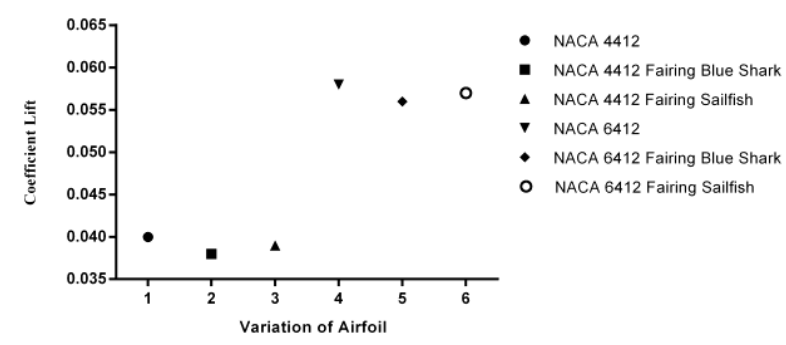

Fig. 5. Coefficient lift.

Of the observations in the get that the addition of the fairing will be able to reduced coefficient lift, coefficient drag, but from two models fairing model that used the blue shark turns out to have a very small value of the fairing model sailfish and shown with NACA 4412 airfoil two models and NACA 6412.

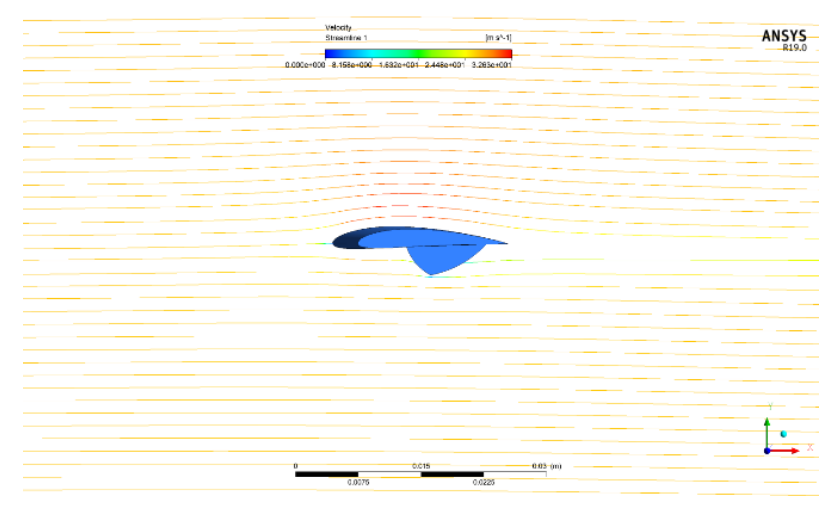

Fig. 6. Streamline velocity us fairing.

Seen that the airfoil experience consider pressure on leading edge, so that with the amount of pressure it will be directly proportional to of the value of the coefficient drag.

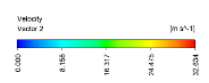

$\underset{\text { ANSYS }}{\text { R19.0 }}$

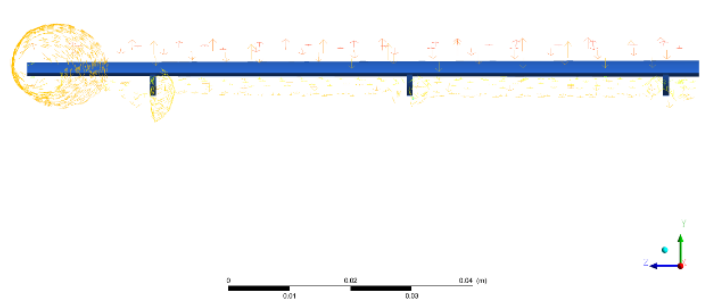

Fig. 7. Vortex region. 
Pressure gradient difference occurs without using fairing. It can look from the fairing in Fig. 7. Pressure difference occurs. With the less pressure on the part of the leading edge, will cause a decline in the value of the coefficient drag. Vortex flow looks that are on the wing tips are quite large. The small direction of the vortex is determine shape of the airfoil and the speed of the flowing stream. Vortex would also be bad for unmanned aerial vehicle (UAV) because the larger vortex happens at the wing tip then will make a unmanned aerial vehicle (UAV) loses the lift or can called downwash.

Fig. 7 with a speed of $27 \mathrm{~m} / \mathrm{s}$, seen that the wing tip vortex flow occurs which quite large, compared to using fairing, with a speed of $27 \mathrm{~m} / \mathrm{s}$ look that still the onset of flow separation on the airfoil and going small vortex at the wing tip. So by using fairing can lower the downwash on the unmanned aerial vehicle (UAV).

In the research [11], according to the research functions of the winglet almost has the same flow phenomena, on the ends of the wings suffered fluid flow vortex caused by the difference in pressure and velocity of flow around the airfoil.

Fig 7. Flow separation occurred and caused by the addition of the fairing, it is causing the air flow do not stream flow vortex and increase the value of the coefficient lift, so that the airfoil is not easily experience a losses of lift force caused by downwash effects.

\section{Conclusions}

Concluded is that the addition of the fairing on the airfoil is known able to reduce the flow of value from coefficient lift, coefficient drag reduction of vortex flow on a wing tip. In determining the fairing model also has a huge impact on the results and the flow pattern that happens.

\section{References}

1. A. Alam, M. Hossain, S. Islam, A. Khan, 3, (2015)

2. H. Xin, no. Amcce, pp. 2031-2034 (2015)

3. T.K. Zhen, M. Zubair, K.A. Ahmad, Chinese J. Aeronaut. 24 (5), 577-583 (2011)

4. A. Bojja, P. Garre, 2 (12), 51-53 (2013)

5. H. Shan, L. Jiang, C. Liu, M. Love, B. Maines, 37, 975-992 (2008)

6. M. Manolesos, S.G. Voutsinas, 142, 130-148 (2015)

7. M. Atkinson, F. Ferguson, no. January, 1-12 (2006)

8. G. Narayan, B. John, Aerosp. Sci. Technol. 58, 328340 (2016)

9. G. Godard, M. Stanislas, 10, 181-191 (2006)

10. O. Madani, M. Medale, O. Imine, B. Imine, Eur. J. Mech. B/Fluids 56, 82-96 (2016)

11. M.A. Azlin, C.F.M. Taib, S. Kasolang, F.H. Muhammad, I, (2011) 